\title{
A Design on Bank Customer Complaints Analysis using Natural Language Processing
}

\author{
Lakshmi KN, Divya G, Devika SP, Yogesh HS, Megha V
}

\begin{abstract}
The banking sector has undergone a major revolution with the advent of digital transformation. The entry of Fintech and tech giants such as Google, Amazon, and Facebook have introduced convenient banking that is easy to understand and use. In this focused condition, banks are understanding the significance of client care and fulfillment and need to give close consideration to the Voice of Customer to improve client experience. By dissecting and getting bits of knowledge from client input, banks will have better data to settle on key choices. In their quest to better understand their customers, banks are seeking artificial intelligence (AI) solutions in the form the of sentiment analysis. What is sentiment analysis? In simple words, sentiment analysis is the process of detecting a customer's reaction to a product, brand, situation or event through texts, posts, reviews, and other digital content. Using sentiment analysis, business leaders can gain deep insight into how their customers think and feel. The analysis can help in tracking customer opinions over a period of time, determine customer segmentation, plan product improvements, prioritize customer service issues, and many more business use cases.
\end{abstract}

Keywords: Artificial Intelligence(AI), Finetech and tech giants, Sentimental analysis;

\section{INTRODUCTION}

The quick increment in client information volume has animated the need to assess such information. Ongoing progress in content mining has permitted unstructured content data including client audits, client grievances and client criticism to be broke down. A lot of work has been attempted to utilize bits of knowledge picked up from content mining to characterize shopper needs to control showcase arranged item advancement. The past research, in any case, has an irritation that characterizes explicit client needs dependent on item includes. So as to conquer the limitation, this paper talks about the utilization of client grievance content mining examination to characterize the genuine needs of customers utilizing the Outcome-Driven Innovation (ODI) approach. This paper gives a system to assessing grievances from clients utilizing the work definition. The ODI-based methodology prompts shopper inactive necessities being set up by customers during preexecution and post-execution phases of item utilize those past techniques can't find.

Revised Manuscript Received on December 15, 2019

Divya G, Ise, Vvce, Mysuru, India. Email: Divyagr1997@Gmail.Com Lakshmi $\mathbf{K} \mathbf{N}$, Ise, Vvce, Mysuru, India. Email: Lakshmikn63@Gmail.Com

Devika S P, Ise, Vvce, Mysuru, India. Email: Devikasp5@Gmail.Com

Yogesh H S, Ise, Vvce, Mysuru, India. Email: Yogeshhs92@Gmail.Com Megha V, Ise, Vvce, Mysuru, India
We present a contextual investigation of stand-type forced air systems to outline how the proposed strategy will characterize client necessities. The study found two needs not identified by experts but considered important.

This work helps identify the criteria of all the points at which consumers want consumer assistance. For instance, a sentence like "The client care of XYZ bank is baffling" - the framework distinguishes "client assistance" as an element, "XYZ bank" as the article and "disappointing" as a negative conclusion. The calculation lands at a connection between the feeling and item to remove pertinent data. Today, a few banks study and track client conduct through sites, exchanges, voice notes, internet-based life, and other advanced channels. The point being, to guide and screen a client's adventure with a bank and how those ways influence the nature of administration or the closeout of monetary items and administrations. Money related organizations are gathering information through surveys or meetings to catch clients suppositions towards explicit item or administration. Dissecting the unstructured information through semantic preparing offers a far-reaching perspective on consumer loyalty; arranging it under negative, unbiased and positive criticism. Utilizing the bits of knowledge, banks can convey better client support. Banks are anxious to mechanize consistence procedures, and data recovery/record search innovation could help with this. Search capacities could permit consistence officials at banks to discover appropriate data among a huge number of computerized records generally rapidly.

\section{RELATED WORK}

[1]The aim of this paper is to examine and analyze data on c onsumer financial complaints, what number of practically identical protests are there in association with a comparable bank or organization or thing Both sets of data come under Credit Uncovering, Mortgage, Debt Collection, Consumer Loan, and Banking Accounting grumblingsBy using tools for data mining,bunch

examination, similarly as farsighted showing, Will be extended for get significant information about grumblings in explicit areas of the Country. The banks that accept customer complaints against them wil 1 analyze the complaint data to find out where the most grum bling is being stored, what things / organizations are causing the most struggles, and other accommodating data.

The model may help banks understand the territory and ki nds of mixups for targets, promoting widespread buyer com mitment to boost wages and profitability. 
[2] The motivation driving this assessment article is to look at the client consistency among the gathering of a client towards the open division and private part banking undertakings in India. The examination Both transversal and transversal illustrated in nature. The inspector attempts to try to explain the client reinforce fulfillment in India's financial piece. Certain framework about the arrangement is utilized for this examination, where the information is aggregated through the assessment. The data is amassed from the various clients of the two banks, The data is collected in the Meerut District, Uttar Pradesh, fr om the different customers of the two banks, that is, PNB an d HDFC Bank oversaw.viz.,. A hundred banks react from each bank were going to after a short time so as to analyze for reasonable and consistent with the point reactions on the possibility of the relationship inbanks. In the present analysis, the association value model produce d by Zeithamal, Parsuraman, and Berry(1998) was used.

[3] To dissect the quantity of grumblings made by bank clients. To recommend a few measures to decrease grumblings. attests that client assistance in banks implies fulfilling the necessities of clients at the opportune time and in the correct way with exactness, unwavering quality, high help speed, security and request office for proficient client assistance. The incredible and overseeing client relationship later on for any business or everyone's matter of fact. Thusly, client center isn't being seen as only a business technique however ought to turn into a corporate strategic (and Varghese, 2003). Great client assistance in banks ought to have three fundamental principles - affability, exactness, and speed. The level of customer care and satisfaction is constrained by a branch territory and structure, collection of organizations, rates, and charges, structures, and frameworks, arrangement and decentralization, mechanization and computerization, centered viability, protesting change and essentially, staff capacities, mindsets, and responses.

[4] The present study introduces you to E-Banking, giving the meaning, function, types and their benefits. It will also show the impact of E-Banking into the person's life. This paper provides the present status of the E-Banking in the market through the analysis of the satisfaction level of the people.

[5] The examination is an endeavor to recognize the elements that add to consumer loyalty with web banking administrations. The component Quality of management like Substantial quality, unwavering quality, sensitivity, dedicati on and empathy have indicated pretty much an incredible effect on consumer loyalty with web banking administrations.

[6] This examination plans to decide the impacts of pictures, surveys believability and personalization include on clients' fulfillment in getting to café recommender applications. This investigation utilizes a quantitative methodology with a sum of 419 gathered respondents. The information assembled inside this investigation is being broke down utilizing numerous relapses utilizing SPSS 22.0. The consequences of this investigation show that photos and surveys believability are influencing client fulfillment on utilizing café recommender applications. Furthermore, giving personalization on a café recommender applications may likewise improve its client fulfillment in getting to the applications.

[7] To apply ordinary language taking care of to Reddit comments about dermatology subjects to assess for attainability and potential for bits of knowledge and commitment There is an absence of research concentrating quiet created information on Reddit, one of the world's most mainstream discussions with dynamic clients inspired by dermatology. Strategies inside normal language handling, a field of man-made reasoning, can break down a lot of content data and concentrate bits of knowledge.

[8]A proposition for Kansei information extraction technique dependent on common language preparing innovation and online item audits considering the advancement of regular language handling innovation and web-based shopping, a modernized strategy to remove Kansei information from online item surveys is initially proposed in this article, and a social extraction strategy to build up the connection between item highlights and client recognitions is additionally given. This article dissects and extricates the Kansei expressions of 10 mice individually utilizing the proposed mechanized strategy, accepting the mouse as the contextual analysis. At that point, three assessment markers including assorted variety, viability, and focus are characterized to survey the technique, which assesses the predominance with the benefit of $19.03 \%$ in decent variety, $6.91 \%$ inadequacy, $22.18 \%$ in the fixation and 8.9 occasions higher in the all out score contrasted and a customary strategy.

[9] The life of such faux reviews degrades the credibility of the complete assessment series, consequently those fake reviews must be recognized and removed. This manner, but, desires to be computerized on account that it's far not possible to carry out it manually in massive assessment collections. Current initiation ID procedures become mindful of creator's dependent on gigantic scale messages, for example, archives. For this purpose, these strategies do now not scale well to brief texts which include online reviews that have restricted features to study from. This paper presents another new approach of writer identification in short texts the usage of combos of machine gaining knowledge of calculations and characteristic language handling strategies. The trials we completed on Yelp assessments gave promising impacts.

[10] The take a look at result suggests that for companies within the banking sector so one can increase their patron retention, they must focus at the customers' pride and feel of belongingness to the agency.

The internal inspection / audit of the bank will address attributes on customer service and 0 .

complaints manageme6fvt7by8uiok,pl.;'not to give due representation to these elements in the final audit rating. The Customer Service Committee has been empowered to review the implementation of the Bank's Code of Commitments to Customers. Any non compliance will be treated as complaint. 


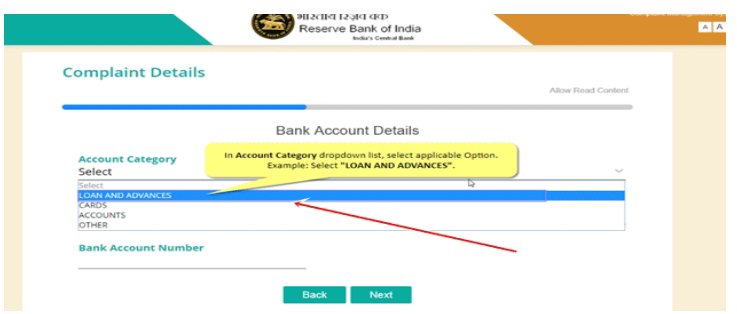

Fig.1. Registration through RBI website

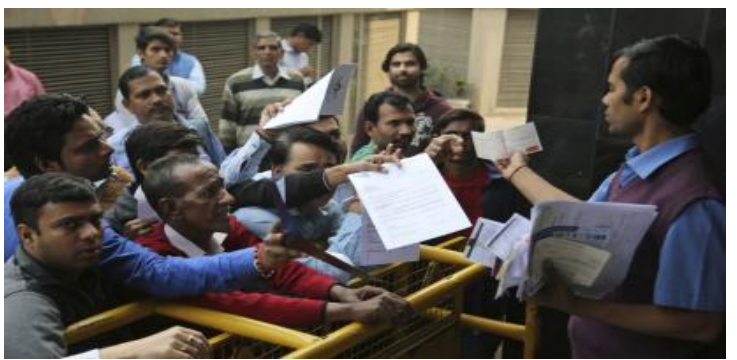

Fig.2. Registration through application

\section{RESULTS AND DISCUSSION}

The overall procedure of customer lawsuits analysis for market-orientated product improvement collects patron proceedings with respect to an item, at that point separates highlight up-and-comers from the unstructured substance of patron lawsuits. To watch the possibility of the procedure to the examination of the procedures, those candidates are first distinguished dependent on the different occupations of the objective item. At that point, optional applicants who superbly affect grouping are chosen. Gathered client claims are assembled the utilization of a grouping procedure based on monster capacities they are identified and different task steps. Examination of bunching results can choose buyer prerequisites With a client application wishes.

NLP is the capacity of machines to understand and analyze human language. It is a part of the Artificial Intelligence (AI) domain with a good sized overlap with Linguistics.

1. DATA COLLECTION: Data mining or ETL (extractrework-load) system to collect a corpus of unstructured statistics.

\section{DATA PREPROCESSING:}

A. Sentence Segmentation: Process of dividing written text into significant gadgets such as words or topics.

B. Tokenization: Segmentation of walking textual content into words.

C. Lemmatization: Removal of inflectional endings to go back the bottom shape .

D. Parts-of-speech tagging: Identification of phrases as nouns, verbs, adjectives and so forth.

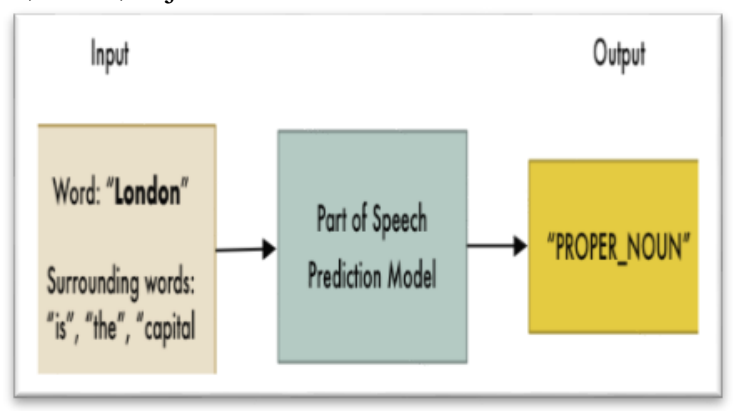

Fig.3. Example of parts-of-speech.

\section{E. Identifying Stop Words}

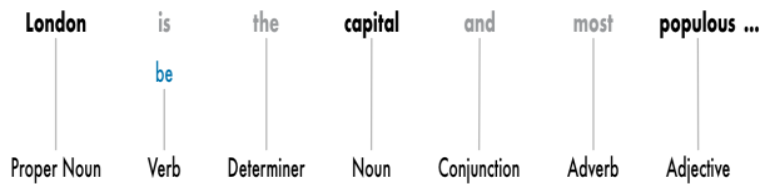

Fig.4. Example of identifying stop words.

we have to consider the criticalness of each word in the sentence. English has a ton of filler words that show up as a rule like "and", "the", and "a". While doing experiences on content, these words present a huge amount of disturbance since they appear undeniably more from time to time than various words.

\section{FEATURE ENGINEERING:}

A. Word Embeddings: Transforming textual content into a significant vector or array of numbers.

B. N-grams: An unigram is a hard and fast of character words inside a report; bi-gram is a set of two adjacent phrases inside a report.

C. TF-IDF esteems: Term-Frequency-Inverse-DocumentFrequency is a numerical measurement speaking to how essential a word is to a report inside a lot of records.

\section{APPLICATION OF NLP ALGORITHMS:}

A. Latent Dirichlet Allocation: Topic modeling algorithm for detecting abstract topics from a set of documents.

B. Support Vector Machine: Classification set of rules for detection of underlying customer sentiment.

C. Long Short-Term Memory Network: Type of repetitive neural networks for gadget translation utilized in Google Translate.

Now allow's look at multiple actual-existence case studies on actual purchaser court cases.

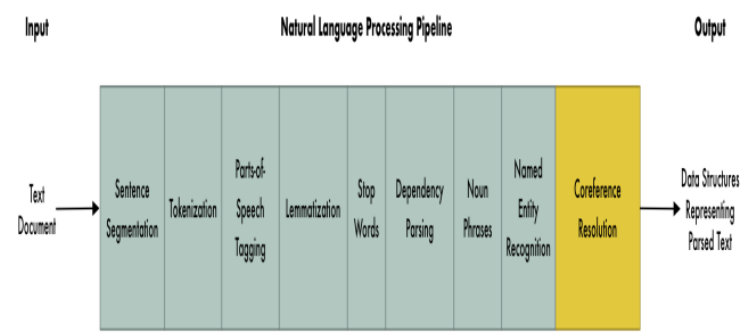

Fig.5. Example of an overall NLP process.

\section{CONCLUSION}

However, herbal languages are extraordinarily complicated systems. Think of a human frame; it includes 11 separate structures (e.G., nervous, digestive and so on.) operating in tandem with each other. Similarly, a human language has several sub-systems along with phonology, morphology, and semantics running seamlessly with every other.

\section{REFERENCES}

1. Lengnick-Hall, C.A. "Customer contributions to quality: A different view of the customer-oriented firm."Acad. Manag. Rev. 1996, 21, 791-824.

2. Nambisan, S. "Designing virtual customer environment for new product development: Toward a

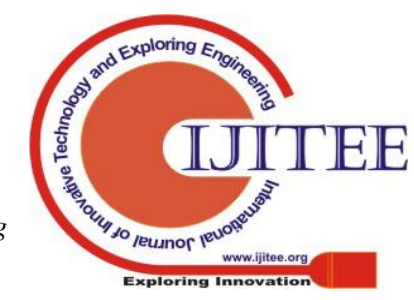


theory." Acad. Manag. Rev. 2002, 27, 392-413.

3. Rigby, D.; Zook, C. "Open-market innovation.” Harv. Bus. Rev. 2002, $80,80-81$.

4. Atuahene-Gima, K. "An Exploratory Analysis of the impact of market orientation on new product performance: A contingency approach. ”J. Prod. Innov. Manag. 1995, 12, 19.

5. Zhan, J.; Loh, H.T.; Liu, Y. "Gather customer concerns from online product reviews-A text summarization approach. Expert Syst." Appl. 2009, 36, 2107-2115 6. Decker, R.; Trusov, M. "Estimating aggregate consumer preferences from online product reviews." Int. J. Res. Mark. 2010, 27, 293-307.

7. Park, Y.; Lee, S. "How to design and utilize online customer centre to support new product concept generation. Expert Syst.” Appl. 2011, 38, $10638-10647$.

8. Aguwa, C.C.; Monplaisir, L.; Turgut, O. "Voice of the customer: Customer satisfaction ratio based analysis. Expert Syst. ”Appl. 2012, 39, 10112-10119.

9. Wang, Y.; Tseng, M.M. "A Naïve Bayes approach to map customer requirements to product variants.” J. Intell. Manuf. 2015, 26, 501-509.

10. Aguwa, C.; Olya, M.H.; Monplaisir, L. "Modeling of fuzzy-based voice of customer for business decision analytics." Knowl.-Based Syst. 2017, $125,136-145$

\section{AUTHORS PROFILE}

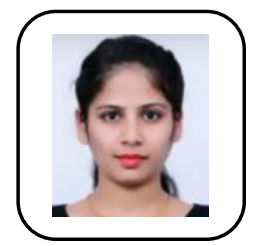

Megha V- working as Assistant Professor in Dept of Information Science and Engineering at Vidya Vardhaka college of Engineering Mysore. Her research interest includes Artificial intelligence and sentiment analysis

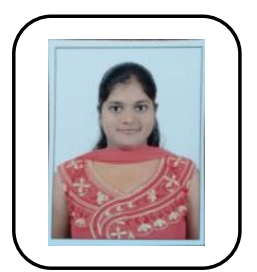

Lakshmi K N of Dept. of Information Science and Engineering at Vidya Vardhaka college of Engineering Mysore. Her research interest includes Artificial intelligence and sentiment analysis

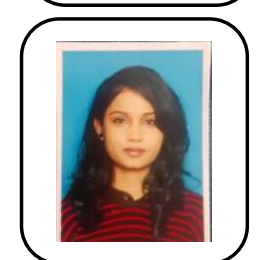

Divya G - of Dept. of Information Science and Engineering at Vidya Vardhaka college of Engineering Mysore. Her research interest includes Artificial intelligence and sentiment analysis

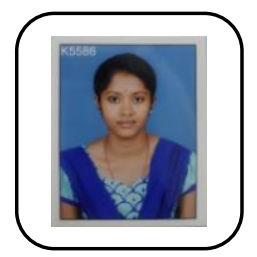

Devika $\mathbf{S} \mathbf{P}$ of Dept. of Information Science and Engineering at Vidya Vardhaka college of Engineering Mysore. Her research interest includes Artificial intelligence and sentiment analysis

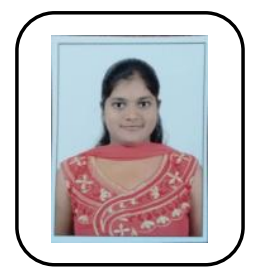

Yogesh H S of Dept. of Information Science and Engineering at Vidya Vardhaka college of Engineering Mysore. Her research interest includes Artificial intelligence and sentiment analysis 